\title{
The distribution of Heterotrissocladius oliveri Saether (Diptera: Chironomidae) in Lake Michigan
}

Michael H. Winnell \& David S. White

Great Lakes Research Division, Institute of Science and Technology, University of Michigan, Ann Arbor, MI 48109 U.S.A.

Address for correspondence: Benthos Laboratory, 1081 North University Building, University of Michigan, Ann Arbor, MI 48109 U.S.A.

Keywords: Heterotrissocladius oliveri, Chironomidae, Diptera, Lake Michigan, distribution, abundance

\begin{abstract}
Fifty one chironomid species were identified from 504 samples collected at depths ranging 8 to $267 \mathrm{~m}$ in Lake Michigan, U.S.A. Heterotrissocladius oliveri Saether occurred in $32 \%$ of these samples and had an average abundance of $22 \mathrm{~m}^{-2}$ which was similar to other estimates from the Great Lakes. Maximum average lake-wide density was at 30 to $60 \mathrm{~m}\left(41 \mathrm{~m}^{-2}\right)$. At depths $\geq 60 \mathrm{~m}, H$. oliveri was the dominant chironomid species comprising $75 \%$ of total Chironomidae. The substrate preference of $H$. oliveri differed within each depth regime considered: at $30-60 \mathrm{~m}, 2-3 \phi$; at $60-120 \mathrm{~m}, 3-5 \phi, 7-9 \phi$; and at $120-180 \mathrm{~m}, 6-8 \phi$. Abundance was notably reduced at all depths in substrates characterized as medium silt $(5-6 \phi)$. On a lakewide basis, the distribution pattern suggested $H$. oliveri was most numerous from 30 to $60 \mathrm{~m}$ along the southwestern, eastern, and northern shorelines and at 60-120 m depths along the southern and eastern shorelines. Increased abundance in the South Basin was concurrent with evidence of increased sedimentation at 60 to $100 \mathrm{~m}$. However, in several other areas of the lake, high densities were associated with medium to very fine sands relatively free of silts and clays. This observation suggested occurrence of $\mathrm{H}$. oliveri was minimally affected by sediment type.

Widely variable, but generally elevated water temperatures likely prevent $H$. oliveri from establishing a substantial population density at depths $<30 \mathrm{~m}$. With increased depth, temperature fluctuation is negligible and food is more stable, though the source is variable. Factors limiting abundance of $H$. oliveri at depths $\geq 30 \mathrm{~m}$ were related to decreased food supply due to distance from shore, food sources of lower value (clays), and, most importantly, to reproductive replenishment.

Although still oligotrophic in nature, high density occurrences in both high and low sedimentation areas of the lake suggest the trophic indicator status of $H$. oliveri might be broader than previously thought.
\end{abstract}

\section{Introduction}

First identified in the Great Lakes as Brillia sp. (Merna, 1960, in Mozley \& Howmiller, 1977), Heterotrissocladius oliveri Saether has been listed as Spaniotoma sp., Hydrobaenus sp., Metriocnemus sp., Orthocladius sp., and Heterotrissocladius subpilosus (Henson, 1966; Brinkhurst et al., 1968; Mozley \& Howmiller, 1977). With the revision of the Heterotrissocladius by Sacther (1975a), the nearctic form is now properly referred to as
$H$. oliveri, while its palaearctic sister species is $H$. subpilosus Kieffer. $H$. oliveri is an indicator of cold stenothermic, ultraoligotrophic to strongly oligotrophic conditions (Saether, 1975b, 1979), which occur over a broad area of the Laurentian Great Lakes, and it is part of a community composed of Pontoporeia hoyi (Amphipoda), Stylodrilus heringianus (Oligochaeta), and Pisidium conventus (Pisidiidae) inhabiting deep, well-oxygenated watcrs. These animals represent an oligotrophic group that covers a greater area of the 


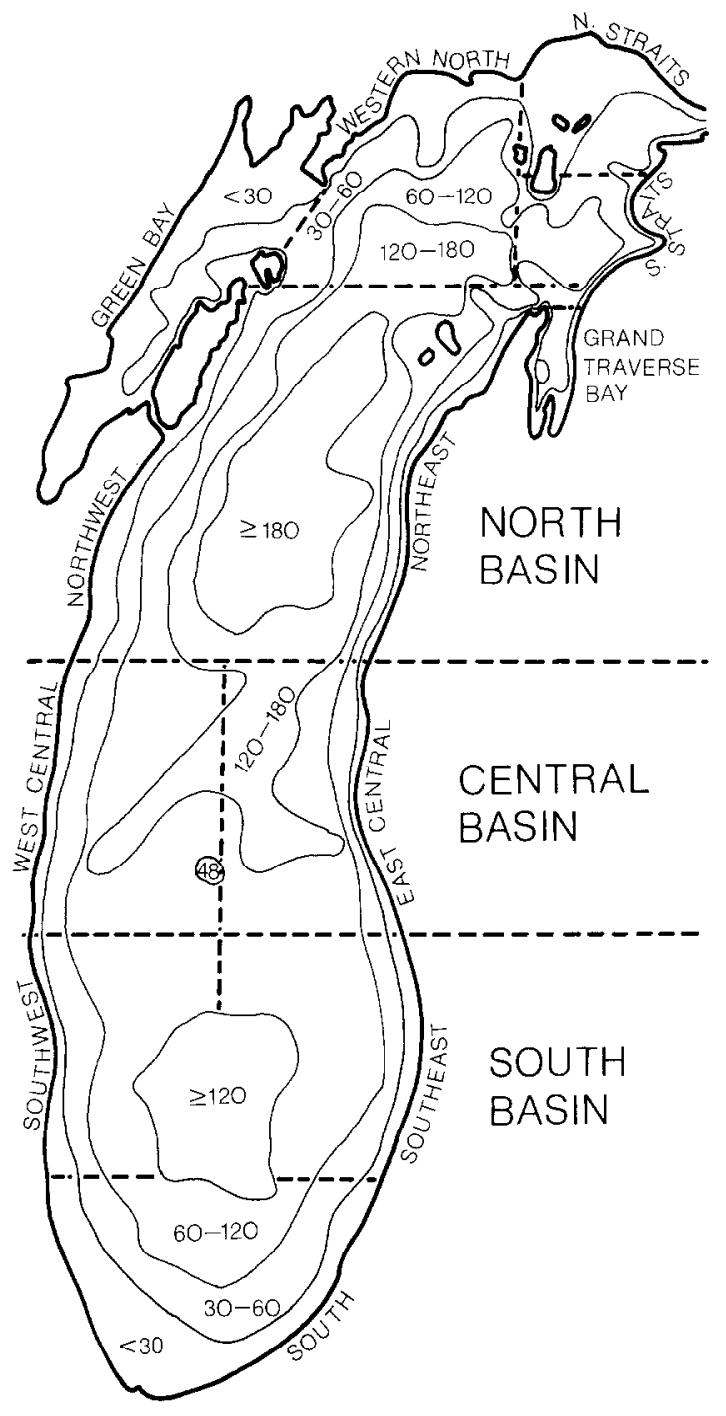

Fig. 1. Areal partitioning of Lake Michigan into major bays and basins with corresponding meter depth regimes. As defined here, shorelines extend from $0-120 \mathrm{~m}$ and were uniquely titled to indicate the location of each within respective basins and the lake in general.

Table 1. Chironomidae collected in 1975 and 1977 from Lake Michigan. Species identified from samples collected at depths $\geq 60 \mathrm{~m}$ indicated by $*$.

\section{Taxon}

Chironominae

Chironomini

Chironomus anthracinus-gr.

Chironomus fluviatilis-gr.

Chironomus halophilus-gr.

Chrionomus semireductus-gr.
Table 1. (Continued)

Taxon

Cryptochironomus cf. rolli

Cryptochironomus sp. 1

Cryptochironomus sp. 2

Dicrotendipes sp.

Harnischia sp.

Microtendipes sp.

Parachironomus cf. abortivus

Parachironomus cf, pectinatellae

Parachironomus sp. 3

Paracladopelma cf. nereis

Paracladopelma cf. undine

* Paracladopelma cf. winnelli

Paralauterborniella sp.

Paratendipes sp.

Phaenopsectra sp.

Polypedilum cf. scalaenum

Polypedilum cf. tuberculum

Pseudochironomus sp.

Robackia demeijerei

Saetheria tylus

Stictochironomus sp.

Tanytarsini

Cladotanytarsus sp.

* Micropsectra sp.

Stempellina sp.

Stempellinella $\mathrm{sp.}$

Tanytarsus cf. curticornis

*Tanytarsus sp.

Zavrelia sp.

Orthocladiinae

Acricotopus sp.

Corynoneura sp.

Cricotopus sp.

Diplocladius sp.

Heterotrissocladius changi

* Heterotrissocladius oliveri

Hydrobaenus sp.

Nanocladius sp.

Parakiefferiella sp.

*Psectrocladius $\mathrm{sp}$.

Pseudosmittia sp.

Synorthocladius sp.

Thienimanniella $\mathrm{sp}$.

Tanypodinae

*Procladius sp.

Diamesinae

Diamesini

Diamesa sp.

Potthastia longimanus

Protanypodini

Protanypus sp.

Prodiamesinae

Monodiamesa depectinata

Monodiamesa tuberculata 
Great Lakes than any other species assemblage (Brinkhurst et al., 1968).

Although $H$. oliveri is widely distributed in the Great Lakes, only a few surveys (Hiltunen, 1969; Kinncy 1972; Nalcpa \& Thomas, 1976; Mozley, 1974, 1975; Cook, 1975; Loveridge \& Cook, 1975) have sampled sufficiently in waters deep enough to estimate its overall abundance, and no studies have attempted to examine lake-wide distribution patterns of $H$. oliveri with respect to either depth or localized areal differences.

In 1975, the Canada Centre for Inland Water conducted a benthic survey of all of Lake Michigan focusing primarily on the deeper areas. These data were supplemented in 1977 by a large series of nearshore transects around the lake under the sponsorship of the U.S. Environmental Protection Agency. Both sets of data were then available to examine lake-wide depth and areal density differences, to ascertain general and specific spatial distribution trends, and to establish lake-wide distribution patterns of $H$. oliveri in Lake Michigan.

\section{Methods}

In August 1975, 273 benthic samples were collected from Lake Michigan by the Canada Contre for Inland Waters (CCIW) aboard the C.S.S. Limnos. One double Shipek grab was taken at each intersection of a $14 \times 14 \mathrm{~km}$ Universal Transverse Mercator (UTM) grid over most of the lake. A $7 \times 7 \mathrm{~km}$ grid was used in Green Bay and the northeast-most corner of the lake. One portion of the double grab was analyzed for benthic organisms and the other used for sediment particle size determinations. Benthos samples were field sorted through a $250 \mu \mathrm{m}$ sieve and preserved with $4 \%$ buffered formalin. These samples and the unsorted samples were obtained by the Great Lakes Research Division in 1977.

As the $14 \times 14 \mathrm{~km}$ UTM grid produced very few shallow or nearshore stations, a second Lake Michigan cruise was undertaken aboard the $R / V$ Simons in July and August 1977 sponsored by the U.S. Environmental Protection Agency. Samples on this cruise were taken along 21 transects evenly spaced around the lake approximately $60 \mathrm{~km}$ apart. Each transect was aligned along the steepest gradient perpendicular to the shoreline. Station depths at each transect were $9 \mathrm{~m}, 18 \mathrm{~m}, 36 \mathrm{~m}$, and $54 \mathrm{~m}$. Two double Shipek grabs were taken at each site. From the first grab, both samples were retained for benthic organisms. From the second grab, one sample was saved for benthos and one for sediment particle size analysis. Benthos samples were elutriated aboard ship using a $100 \mu \mathrm{m}$ sieve and preserved in $4 \%$ buffered formalin for later sorting. Transect 16 from the North Straits area of the northeast corner of the lake did not contain a $54 \mathrm{~m}$ station as most of this area is fairly shallow. A total of 251 benthic samples were collected in the nearshore survey. Of the 524 samples available to us, the chironomids were missing from 20 samples, thereby yielding 504 samples for the lake-wide analyses.

$H$. oliveri occurring in samples collected were analyzed with respect to depth, substrate particle size, and location (area) in the lake. Depth of occurrence was partitioned such that the littoral and sublittoral zones were estimated by the $<30 \mathrm{~m}$ depth regime, and the profundal zone was estimated by the $30-60-, 60-120-, 120-180$-, and $\geq 180-\mathrm{m}$ depth regimes. Substrates were characterized by particle size determinations based on units of phi $(\phi)$. Occurrence of $H$. oliveri with respect to location within the lake was based on geographic partitioning of the lake and superimposing the previously noted depth regimes (Fig. 1). The $48 \mathrm{~m}$ station circled in the West Central portion of the Central Basin denotes its deviation from otherwise considerably deeper water.

In several instances, densities at given location/depth strata were strongly dependent upon a single observation. To illustrate this dependence, all strata densities were recalculated as follows:

(Mean density $\times \mathrm{n})-$ (Maximum observed density) $/ \mathrm{n}-1$, where $\mathrm{n}=$ number of samples in a given stratum.

\section{Results}

\section{Relationship to depth}

Fifty one species of chironomids were identified from the 504 samples comprising the Lake Michigan data sets. Depths ranged from 8 to $267 \mathrm{~m}$ $(\bar{X}=61 \mathrm{~m}$ ) (Table 1). Heterotrissocladius oliveri occurred in $32 \%$ of all samples collected with an aver- 
age density of $22 \mathrm{~m}^{-2}$. Mean density of $H$. oliveri ranged from a maximum of $41 \mathrm{~m}^{-2}$ in 30 to $60 \mathrm{~m}$ deep samples to a minimum of $1 \mathrm{~m}^{-2}$ at sample depths $\geq 180 \mathrm{~m}$ (Table 2 ). The greatest percentage of total Chironomidae for $H$. oliveri and percent occurrence among samples collected was in the 60 to $120 \mathrm{~m}$ depth range ( 81 and $57 \%$, respectively). In general, $H$. oliveri occurred abundantly and consistently between 30 and $180 \mathrm{~m}$ deep in Lake Michigan.

While all 51 species occurred at depths $<60 \mathrm{~m}$, only 6 species were identified from samples $\geq 60 \mathrm{~m}$ $(\overline{\mathrm{X}}=126 \mathrm{~m})$. At depths $\geq 60 \mathrm{~m}, H$. oliveri averaged $19 \mathrm{~m}^{-2}$, comprised $75 \%$ of total Chironomidae, and occurred in $42 \%$ of all samples collected. Of the other 5 chironomid species at depths $\geq 60 \mathrm{~m}$, only the density of a Micropsectra sp. $\left(4 \mathrm{~m}^{-2}\right)$ exceeded $1 \mathrm{~m}^{-2}$. This species made up $17 \%$ of total Chironomidae and occurred in $7 \%$ of all samples. Paracladopelma winnelli, Procladius sp., Psectrocladius $\mathrm{sp}$., and Tanytarsus sp. were represented by no more than 1 to 6 individuals total for all samples collected at $\geq 60 \mathrm{~m}$ and together comprised the remaining $8 \%$ of the chironomid population in the deepest portion of the lake.

\section{Relationship to substrate type}

The substrate preference of $H$. oliveri was different within each depth regime considered. At 30 to $60 \mathrm{~m}$, greatest numbers of $H$. oliveri occurred in fine sand $(2-3 \phi)$; at 60 to $120 \mathrm{~m}$ in very fine sand to coarsesilt $(3-5 \phi)$ and very fine silt to coarse clay $(7-9 \phi)$; and at 120 to $180 \mathrm{~m}$ in fine silt and very fine silt $(6-8 \phi)$ (Fig. 2). The shallowest and

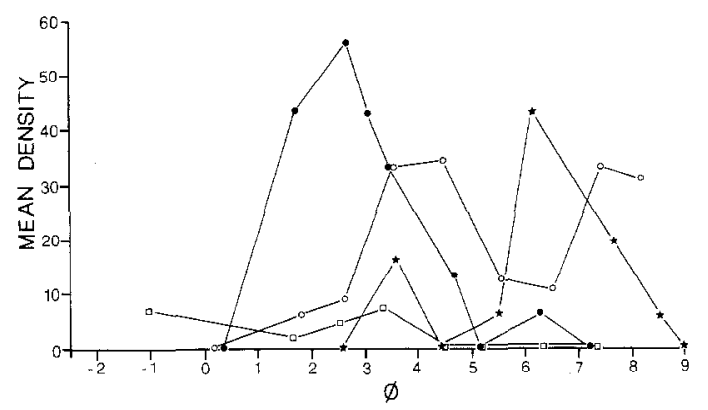

Fig. 2. Mean density (no. $\mathrm{m}^{-2}$ ) for Heterotrissocladius oliveri within the range of sediment types (units of $\phi$ ) at $<30 \mathrm{~m}$ (squares), 30-60 m (solid circles), 60-120 m (open circles), and $\geq 120 \mathrm{~m}$ (stars). deepest depth regimes were excluded in this analysis, because occurrence of $H$. oliveri was minimal. Between 30 to $180 \mathrm{~m}$ deep, the only substrate type in which $H$. oliveri densities were consistently reduced was medium silt $(5-6 \phi)$.

\section{Distribution in Lake Michigan}

Plots generated from the CCIW (Fig. 3) and EPA (Fig. 4) surveys show lake-wide distribution and abundance patterns for $H$. oliveri. Based on the defined areas within the lake (Fig. 1), H. oliveri density did not exceed $8 \%\left(15 \mathrm{~m}^{-2}\right)$ of total

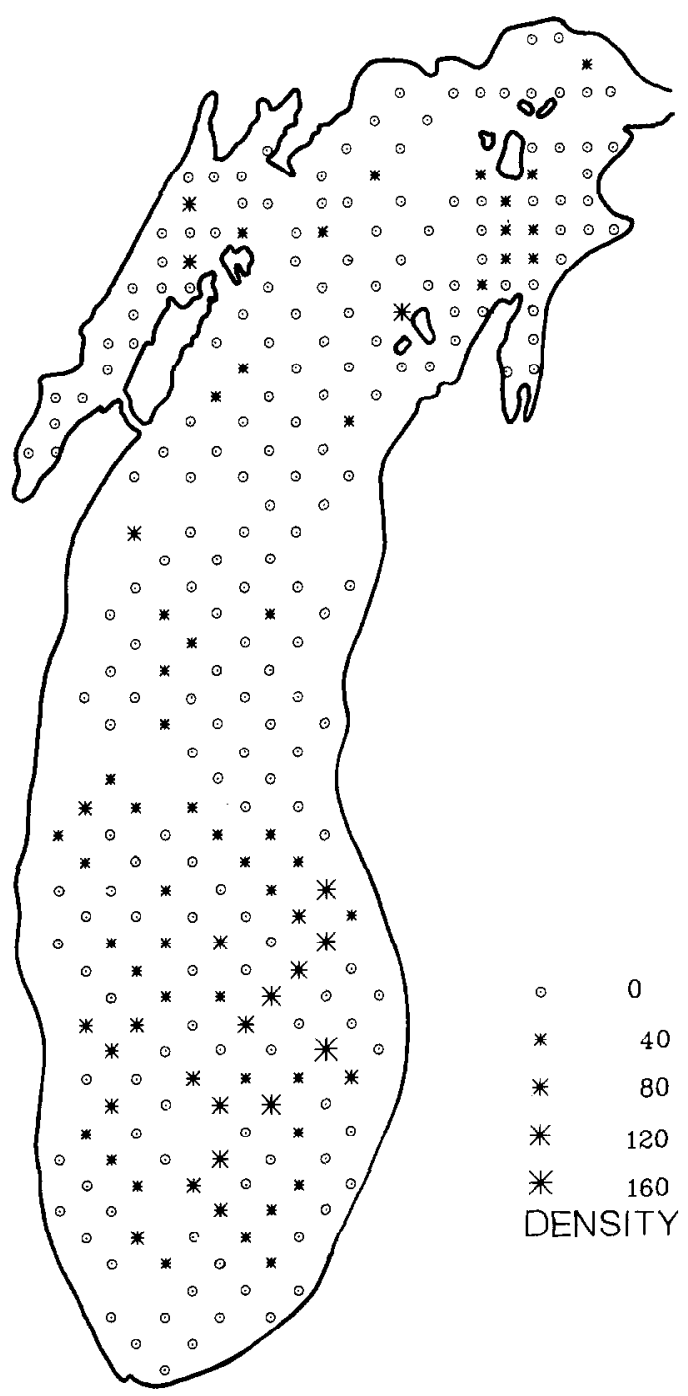

Fig. 3. Distribution and density of Heterotrissocladius oliveri in Lake Michigan based on the CCIW sample grid (see Methods), $n=1$ for each point. 
Table 2. Occurrence of $H$. oliveri among selected areas within Lake Michigan (see Fig. 1 for location of lake areas). Density expressed in numbers per $\mathrm{m}^{-2}$. Relative density is percentage of total Chironomidae. Frequency of occurrence is percent occurrence among samples collected. Number of samples collected is $\mathrm{n}$. Actual number of samples examined for $H$. oliveri is in parentheses.

\begin{tabular}{|c|c|c|c|c|c|c|}
\hline Lake area & $\begin{array}{l}\text { Mean } \\
\text { density }\end{array}$ & $\begin{array}{l}\text { Relative } \\
\text { density }(\%)\end{array}$ & $\begin{array}{l}\text { Frequency of } \\
\text { occurrence }(\%)\end{array}$ & $\begin{array}{l}\text { Mean } \\
\text { depth (m) }\end{array}$ & $\begin{array}{l}\text { Mean } \\
\phi\end{array}$ & $\mathrm{n}$ \\
\hline$<30 \mathrm{~m}$ & 4.2 & $<1$ & 7 & 15 & 2.00 & 168 \\
\hline \multicolumn{7}{|l|}{ Shoreline } \\
\hline South & 0 & 0 & 0 & 16 & 2.56 & 30 \\
\hline Southwestern & 0 & 0 & 0 & 15 & 0.05 & 13 \\
\hline Southeastern & 0 & 0 & 0 & 15 & 2.69 & 14 \\
\hline West central & 4.2 & 1 & 8 & 14 & 3.27 & 12 \\
\hline East central & 2.1 & $<1$ & 8 & 14 & 2.20 & 12 \\
\hline Northwestern & 1.3 & $<1$ & 5 & 14 & 1.46 & 19 \\
\hline Northeastern & 13.2 & $<1$ & 11 & 13 & 1.50 & 19 \\
\hline Western North & 12.5 & 1 & 14 & 14 & 0.31 & 14 \\
\hline North Straits & 1.9 & $<1$ & 8 & 17 & 2.62 & 14 (13) \\
\hline South Straits & 4.2 & $<1$ & 17 & 14 & 1.26 & 6 \\
\hline Green Bay & 7.8 & 7 & 19 & 18 & 3.17 & $17(16)$ \\
\hline Grand Traverse Bay & - & - & - & - & - & - \\
\hline $30-60 \mathrm{~m}$ & 41.4 & 41 & 47 & 45 & 3.07 & $176(172)$ \\
\hline \multicolumn{7}{|l|}{ Shoreline } \\
\hline South & 10.6 & 28 & 35 & 46 & 3.40 & $27 \quad(26)$ \\
\hline Southwestern & 55.8 & 78 & 77 & 45 & 2.58 & 13 \\
\hline Southeastern & 20.0 & 50 & 40 & 46 & 4.56 & 14 \\
\hline West central & 14.3 & 53 & 50 & 45 & 3.07 & 14 \\
\hline East central & 59.6 & 74 & 69 & 44 & 2.85 & 14 \\
\hline Northwestern & 12.5 & 14 & 27 & 45 & 2.60 & 22 \\
\hline Northeastcrn & 84.4 & 50 & 71 & 46 & 2.11 & $22 \quad(21)$ \\
\hline Western North & 59.5 & 56 & 33 & 46 & 2.51 & 21 \\
\hline North Straits & 66.7 & 21 & 33 & 35 & 4.06 & $7 \quad(6)$ \\
\hline South Straits & 87.5 & 27 & 70 & 47 & 2.41 & $11(10)$ \\
\hline Green Bay & 3.1 & 14 & 13 & 36 & 6.36 & 8 \\
\hline Grand Traverse Bay & 0 & 0 & 0 & 42 & 2.42 & 3 \\
\hline $\begin{array}{c}60-120 \mathrm{~m} \\
\text { Shoreline }\end{array}$ & 25.9 & 81 & 57 & 90 & 5.19 & $97 \quad(88)$ \\
\hline South & 35.7 & 77 & \multicolumn{4}{|c|}{ Shoreline } \\
\hline Southwestern & 26.8 & 100 & 64 & 87 & $\begin{array}{l}5.35 \\
5.17\end{array}$ & $\begin{array}{rr}8 & (1) \\
15 & (14)\end{array}$ \\
\hline Southeastern & 51.6 & 77 & 69 & 88 & 6.51 & 18 (16) \\
\hline West central & 12.5 & 100 & 44 & 89 & 4.77 & $17 \quad(16)$ \\
\hline East central & 22.9 & 100 & 42 & 95 & 5.90 & 12 \\
\hline Northwestern & 8.3 & 100 & 33 & 94 & 3.68 & 6 \\
\hline Northeastern & 25.0 & 100 & 50 & 94 & 5.09 & (4) \\
\hline Western North & 12.5 & 75 & 50 & 98 & 5.53 & 6 \\
\hline North Straits & - & - & - & - & - & - \\
\hline South Straits & 17.9 & 42 & 71 & 87 & 3.14 & (7) \\
\hline Green Bay & - & - & - & - & - & - \\
\hline Grand Traverse Bay & - & - & - & 107 & - & (0) \\
\hline $120-180 \mathrm{~m}$ & 15.6 & 62 & 32 & 144 & 7.04 & $55 \quad(53)$ \\
\hline \multicolumn{7}{|l|}{ Basin } \\
\hline South & 25.0 & 50 & 36 & 139 & 7.93 & 14 \\
\hline Central & 20.0 & 68 & 47 & 142 & 6.82 & 15 \\
\hline North (lower) & 9.7 & 100 & 28 & 148 & 6.61 & $19 \quad(18)$ \\
\hline North (upper) & 0 & 0 & 0 & 149 & 7.52 & $7 \quad(6)$ \\
\hline \multicolumn{7}{|l|}{$\geq 180 \mathrm{~m}$} \\
\hline \multicolumn{7}{|l|}{ Basin } \\
\hline North (lower) & 1.1 & 50 & 4 & 219 & 8.48 & 23 \\
\hline All depths & 21.7 & 4 & 32 & 61 & 3.78 & $521(504)$ \\
\hline
\end{tabular}




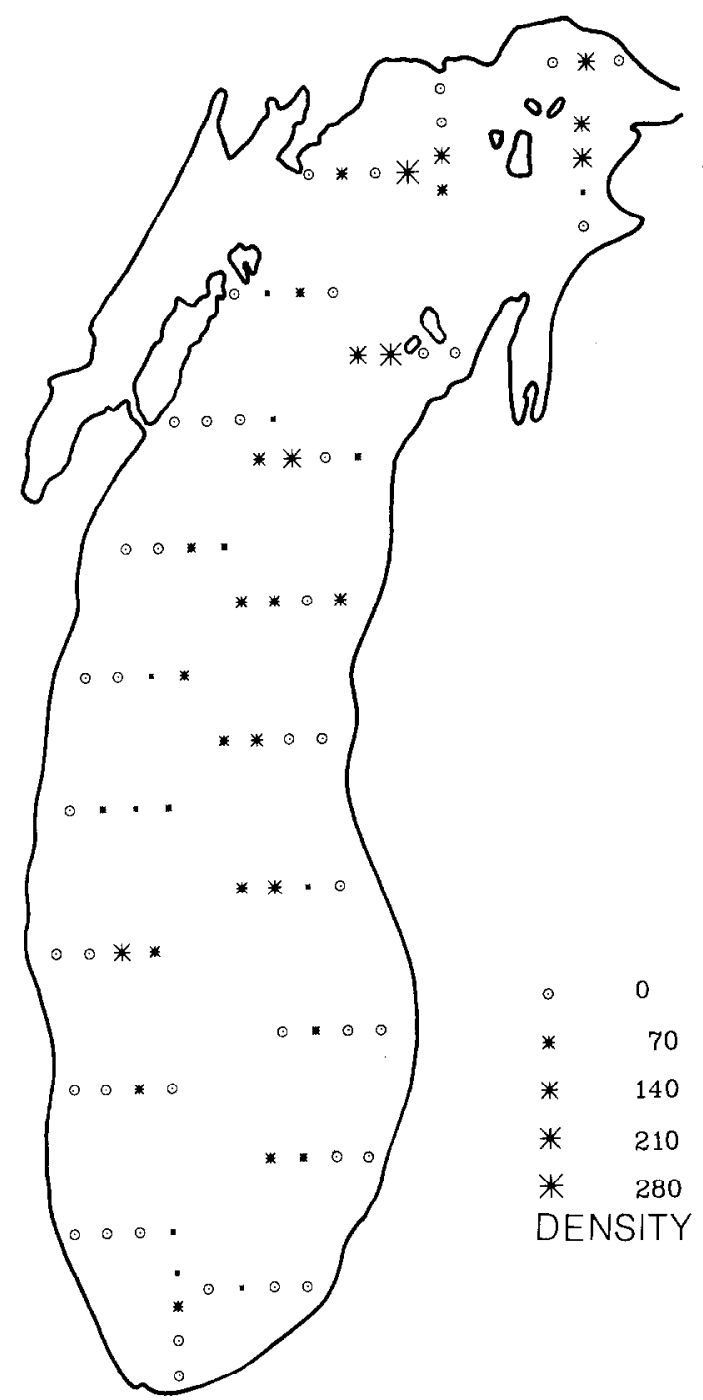

Fig. 4. Distribution and mean densities of Heterotrissocladius oliveri in Lake Michigan based on the EPA sample grid (see Methods), $n=3$ for each point. Location of points along each transect on map do not indicate distance from shore nor exact positioning of station depths $(9,18,36$, and $54 \mathrm{~m})$ but rather are intended to display relative density differences among transects and stations within transects.

Chironomidae, and frequency of occurrence did not exceed $20 \%$ at depths $<30 \mathrm{~m}$ in any area. I ake-wide abundances were maximal at $30-60 \mathrm{~m}$ in areas along the East Central shoreline northward and westward to near Green Bay. In remaining areas of the lake, high abundance occurred along the Southwestern shoreline at $30-60 \mathrm{~m}$. Lowest densities at $30-60 \mathrm{~m}$ were noted along the South shoreline, along the West Central and Northwestern shorelines, and in Green Bay itself. In general, at depths $30-60 \mathrm{~m}$, the eastern and northern shorelines of Lake Michigan supported greater densities of $H$. oliveri than did the southern and western shorelines.

At $60-120 \mathrm{~m}$, a density distribution pattern similar to that for $30-60 \mathrm{~m}$ was evident except it was more restricted to the southern and midnorthern areas of the lake. Densities ranged 23-52 $\mathrm{m}^{-2}$ from the Southwestern shoreline, eastward and northward along the eastern shoreline. All remaining areas of the lake at $60-120 \mathrm{~m}$ averaged $8-18 \mathrm{~m}^{-2}$. In general, the southern and eastern shorelines supported greater densities of $H$. oliveri at $60-120 \mathrm{~m}$ than did the northern and western shorelines.

At depths $\geq 120 \mathrm{~m}$, similar densities of $H$. oliveri were noted in the South $\left(25 \mathrm{~m}^{-2}\right)$ and Central $\left(20 \mathrm{~m}^{2}\right)$ Basins (Table 2). In the North Basin, densities averaged $<10 \mathrm{~m}^{-2}$, but with none found in the northern-most region. In general, there was a steady decrease in $H$. oliveri density in a northerly direction at depths $\geq 120 \mathrm{~m}$.

When examining depth, substrate type, and lakewide occurrence, several distributional patterns were evident (Fig. 5). At depths $<30 \mathrm{~m}$, observed densities either were zero or were largely dependent upon a single sample estimate regardless of area of occurrence in the lake. At $30-60 \mathrm{~m}$, the variability of areal abundances was low in all areas of the lake except along the northern-most shoreline. In addition, nearly all areas $30-60 \mathrm{~m}$ deep occurred in nondepositional zones of the lake $(<4 \phi$, see Cahill 1981). At $60-120 \mathrm{~m}$, the location of nearly all areas in this depth regime were in transitional zones of the lake (4-7 $\phi$, see Cahill 1981). In this latter depth regime, densities in the northern-most areas were the most variable of the areas. In the deepest areas of the lake ( $\geq 120 \mathrm{~m}$ ), densities were similarly variable and occurred in depositional or near depositional zones of the lake ( $\geq 7 \phi$, see Cahill 1981).

\section{Discussion}

Reported abundances and distributions of $H$. oliveri in the Great Lakes are quite variable. Hiltunen (1969) gave an average of $239 \mathrm{~m}^{-2}$ at c. $90 \mathrm{~m}$ and $119 \mathrm{~m}^{-2}$ at 180 to $225 \mathrm{~m}$ depths in 


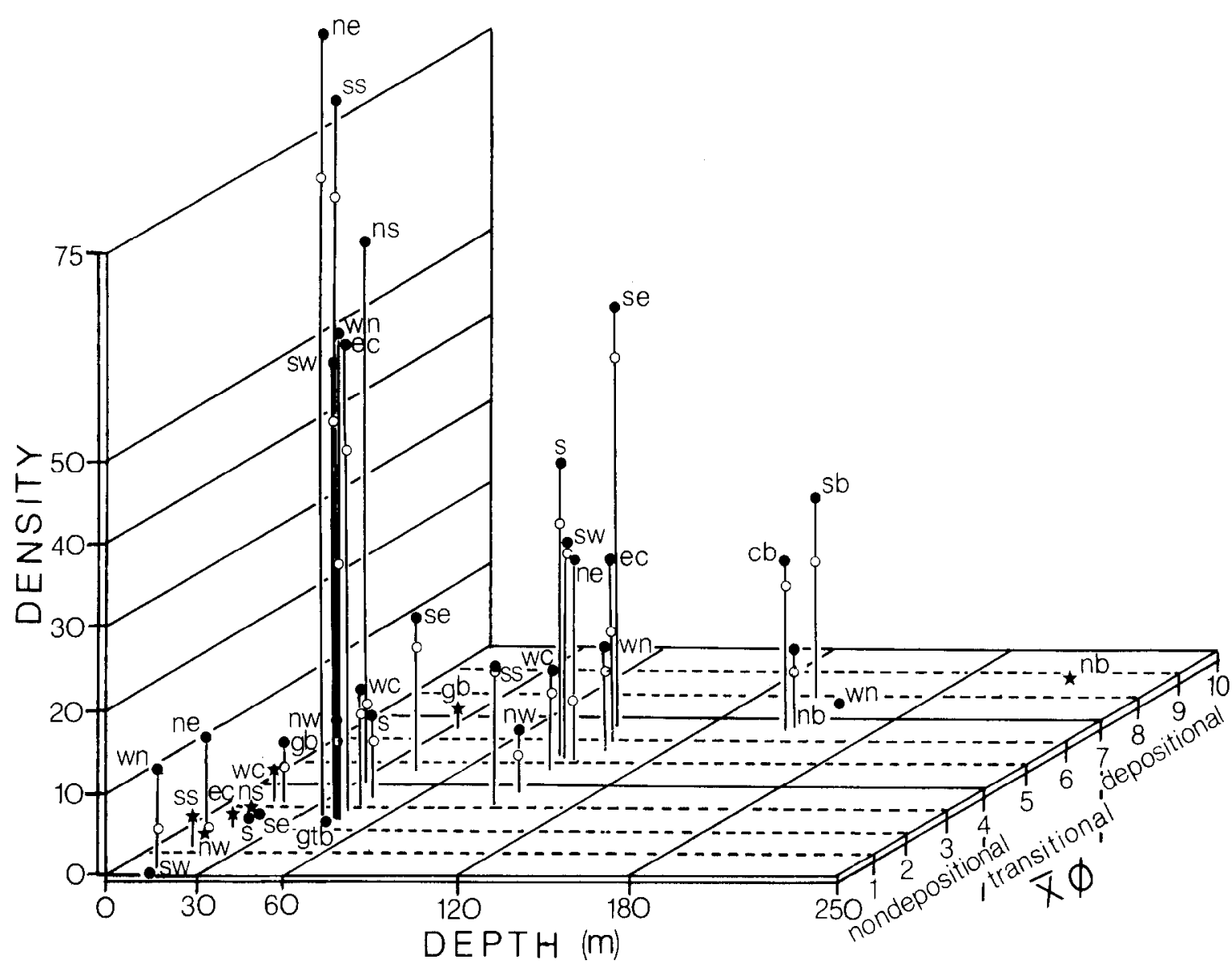

Fig. 5. Three dimensional relationship of average density (no. $\mathrm{m}(-2))$, average depth $(<30,30-60,60-120,120-180$, and $\geq 180 \mathrm{~m}$ ), and mean phi $(\phi)$ for each area (see Fig. 4) of Lake Michigan. Areas within the lake have been abbreviated as follows: $s=s o u t h$, $\mathrm{se}=$ southeast, $\mathrm{sw}=$ southwest, $\mathrm{sb}=$ south basin, $\mathrm{ec}=$ east central, $\mathrm{wc}=$ west central, $\mathrm{cb}=$ central basin, ne $=$ northeast, $\mathrm{nw}=\mathrm{northwest}$, $\mathrm{nb}=$ north basin, wn = western north, $\mathrm{ns}=$ north straits, $\mathrm{ss}=$ south straits, gb $=$ Green Bay, and gtb = Grand Traversc Bay. Mean densities based on all samples in each area, depth, and phi stratum and are denoted by solid circles. Open circles denote recalculated mean densities with the largest single observation removed. Strata with stars denote all except one sample were devoid of $H$. oliveri.

Lake Ontario. However, for the same lake, densities listed by Kinney (1972) averaged only $14-16 \mathrm{~m}^{-2}$ at depths $>47 \mathrm{~m}$, and densities from Nalepa and Thomas (1976) only $3-4 \mathrm{~m}^{-2}$ at depth $>50 \mathrm{~m}$. $H$. oliveri is apparently absent from the western and central basins of Lake Erie (Brinkhurst, 1969). For Lake Huron, Heterotrissocladius sp. (=Spaniotoma) average density was $7 \mathrm{~m}^{-2}$ (Teter, 1960 ), assuming all specimens from 'deep water' stations $(25-119 \mathrm{~m})$ were $H$. oliveri. Averaging density values reported by Loveridge \& Cook (1975) from Georgian Bay and from the North Channel, Lake Huron, $H$. oliveri density was $41 \mathrm{~m}^{-2}$ at stations 11 to $151 \mathrm{~m}$ deep. Similarly, in Lake Superior,
Heterotrissocladius sp. averaged $14 \mathrm{~m}^{-2}$ from 11 to $379 \mathrm{~m}$ deep based on values we recalculated from Cook (1975). Within Lake Michigan, the lakewide average density of $H$. oliveri $\left(22 \mathrm{~m}^{-2}\right)$ reported here was not strongly dissimilar to that of other Laurentian Great Lakes. With the exception of the unusually high densities reported by Hiltunen (1969), mean Great Lakes abundances of $H$. oliveri tend to be less than $40-50 \mathrm{~m}^{-2}$.

Occurrence of $H$. oliveri is affected by many factors, but central to these are the three interrelated factors of sediment type, depth, and temperature. Being a cold stenotherm occurring primarily in ultraoligotrophic to strongly oligotrophic water 
(Saether, 1975b, 1979) and feeding primarily by ingestion of silty-detrital material (Davies, 1975), very limited occurrence at depths $<30 \mathrm{~m}$ was expected. However, temperature as opposed to sediment type is likely the primary factor controlling occurrence at depths $<30 \mathrm{~m}$ as average mean phi $(2.00 \phi)$ at depths $<30 \mathrm{~m}$ differed only slightly from that at $30-60 \mathrm{~m}(3.07 \phi)$, but $H$. oliveri densities differed by an order of magnitude $\left(4 \mathrm{~m}^{-2}\right.$ and $41 \mathrm{~m}^{-2}$, respectively). Because temperature varies considerably in the shallower waters of the lake both seasonally and within a period of a few hours (Mozley \& Winnell, 1975) and is more continuously depressed at depths $\geq 30 \mathrm{~m}$, we conclude that temperature more than substrate controls the near-shore occurrence of $H$. oliveri.

At depths $\geq 30 \mathrm{~m}$ where temperature is stable, factors that control occurrence of $H$. oliveri are more difficult to distinguish. Edgington \& Robbins (1975) demonstrated that maximum sedimentation occurs along the eastern shoreline of the South Basin of Lake Michigan between 60 and $100 \mathrm{~m}$. Maximum abundance of $H$. oliveri in the South Basin generally occurred at $60-120 \mathrm{~m}$, which was most strongly evident along the Southeastern Shoreline (Table 2) implying elevated $H$. oliveri abundances are related to increased sedimentation. In this area of higher deposition, average grain size was regularly near 6-7 $\phi$ (fine silt).

However, even higher densities occurred along the northern portion of the eastern shoreline largely in high wave-energy environments at $30-60 \mathrm{~m}$. At these locations, predominant medium to very fine sands are mostly free of silts and clays, imply-

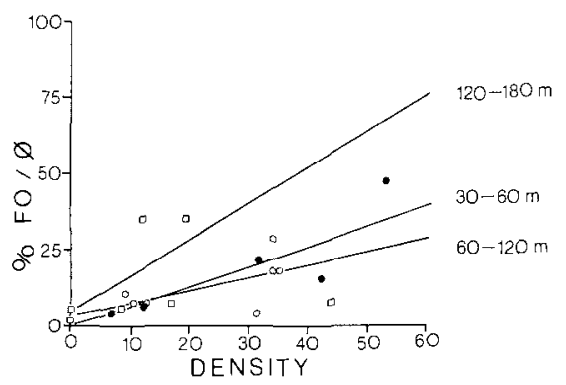

Fig. 6. Linear regression of mean abundance (no. $\mathrm{m}^{-2}$ ) and percent frequency of occurrence (number of samples with Heterotrissocladius oliveri present divided by total number of samples) within each unit of phi $(\% \mathrm{FO} / \phi)$ at $30-60 \mathrm{~m}$ (solid circles), $60-120 \mathrm{~m}$ (open circles), and $120-180 \mathrm{~m}$ (squares) in Lake Michigan. ing minimal deposition. When comparing the percentage of samples characterized by each phi size against mean density of $H$. oliveri within the depth ranges $30-60,60-120$, and $120-180 \mathrm{~m}$, there was a positive correlation $\left(\mathrm{r}^{2}=0.84,0.51\right.$, and 0.40 , respectively) (Fig. 6). The relationship suggests that, regardless of depth regime, maximum numbers of $H$. oliveri occur in the substrate type most common to a particular depth regime. We conclude from this that occurrence of $\boldsymbol{H}$. oliveri is minimally dependent upon substrate type at depths $<180 \mathrm{~m}$.

Factors which we feel affect the occurrence of $H$. oliveri are distance from shore as it affects the amount and quality of food arriving at a site and reproductive success. The general distribution pattern observed at depths $\geq 30 \mathrm{~m}$ is one of decreasing density with increasing depth (Table 2). Low densities of $H$. oliveri at these depths, but most particularly at depths $\geq 180 \mathrm{~m}$, may be more strongly related to reproductive success than to food supply as food supply should be maximal at $35-100 \mathrm{~m}$. The likelihood of an egg or early instar larva migrating through the water column to reach the bottom at $200 \mathrm{~m}$ and successfully establishing itself should be considerably lower than that at $100 \mathrm{~m}$. Potential difficulties for the early pelagic stages include currents or storms, which might increase the amount of time needed to reach the bottom. Under these conditions, increased time in the water column increases chances of predation or mishap and ultimately reduces the number of eggs or larvae reaching the bottom. Reproductive success in combination with food supply function strongly to reduce the abundance of $H$. oliveri at depths $>30 \mathrm{~m}$.

Based on the above interpretations, we conclude that established, regularly occurring populations of $H$. oliveri are limited to depths where water temperatures are consistently low, where the probability of reproductive success is moderate, and where distance from shore provides a moderate amount of food input. In areas of the lake where these three conditions are met, $H$. oliveri occurs abundantly in a variety of substrates having widely disparate quantities of silty-detrital food sources. $H$. oliveri appears to be able to survive in a variety of deepwater habitats and might best be described as a generalist. This mode is most sensible, given the stable, but harsh environment which an egg or first instar larva first encounters. 
High density occurrence in areas experiencing quite variable sedimentation rates suggests to a greater degree that occurrence of $H$. oliveri may not be as narrowly confined to $\alpha$ - and $\beta$ oligotrophic conditions (Saether, 1979) as previously thought. High densities reported by at least one study of Lake Ontario (Hiltunen, 1969) and moderate abundances in the Southern Basin of Lake Michigan in conjunction with high sedimentation rates suggest that, although $H$. oliveri is the dominant chironomid in ultraoligotrophic to strongly oligotrophic conditions, its occurrence does not necessarily imply that these conditions prevail wherever $H$. oliveri is found. It is not possible to determine whether $H$. oliveri distributions and abundances have increased or decreased due to eutrophication, particularly in the Southern Basin of Lake Michigan (Schelske et al., 1983), because no historical species abundances records for Chironomidae are available. It is thought that excessive increases in sedimentation accompanying increased eutrophication in portions of Lake Erie decreased or eliminated the occurrence of H. oliveri (Brinkhurst, 1969). Within the limits of these processes in Lake Michigan, the density response of $H$. oliveri was variable and leads us to conclude that its trophic status may be broader, although still oligotrophic in nature.

\section{Acknowledgements}

We appreciate the many dedicated and helpful people who sorted and identified the animals and organized the data upon which this paper is based, in particular, D. Lauritsen, Z. Batac-Catalan, and C. Millenbach. We thank N. Watson and the Canada Centre for Inland Waters for access to their collections. Research was supported in part under contract from the Indiana \& Michigan Power Company and by a grant from the U.S. Environmental Protection Agency originally to S. Mozley. Contribution No. 421 from the Great Lakes Research Division.

\section{References}

Brinkhurst, R. O., 1969. Changes in the benthos of Lakes Erie and Ontario. Bull. Buffalo Soc. Nat. Sci. 25: 45-65.
Brinkhurst, R. O., A. L. Hamilton \& H. B. Herrington, 1968. Components of the bottom fauna of the St. Lawrence, Great Lakes. Univ. Toronto Gt lakes Inst. prelim. Rep. 33, 50 pp.

Cahill, R. A., 1981. Geochemistry of recent Lake Michigan sediments. Ill. St. Geol. Surv., Cir. 517, Champaign, Ill., 94 pp.

Cook, D. G., 1975. A preliminary report on the benthic macroinvertebrates of Lake Superior. Fish. Res. Bd Can. tech. Rep. $572,44 \mathrm{pp}$.

Davies, I. H., 1975. Selective feeding in some arctic Chironomidae. Verh. int. Ver. Limnol. 19: 3149-3154.

Edgington, D. N. \& J. A. Robbins, 1975. The behavior of plutonium and other long-lived radionuclides in Lake Michigan: II. Patterns of deposition in the sediments. Int. Atomic Energy Ass. Symp. on the Environ. Effects of nuclear power generation. Helsinki, Finland. IAEASM/198/40, 245-260.

Henson, E. B., 1966. A review of Great Lakes benthos research. Univ. Mich., Gt Lakes Res. Div. Publ. 14: 37-54.

Hiltunen, J. K., 1969. The benthic macrofauna of Lake Ontario. Gt Lakes Fish. Comm. tech. Rep. 14: 39-50.

Kinney, W. L., 1972. The macrobenthos of Lake Ontario. In Proc. 15th Conf. Gt Lakes Res., Int. Ass. Gt Lakes Res.: 53-79.

Loveridge, C. C. \& D. G. Cook, 1975. A preliminary report on the benthic macroinvertebrates of Georgian Bay and North Channel. Fish. Mar. Serv. tech. Rep. 610, 53 pp.

Merna, J. W., 1960. A benthological investigation of Lake Michigan. M.Sci. Thesis, Mich. St. Univ., East Lansing, Mich., 74 pp.

Mozley, S. C., 1974. Preoperational distribution of benthic macroinvertebrates in Lake Michigan near the Cook Nuclear Power Plant. In: E. Scibcl, E. \& J. C. Aycrs (cds), The biological, chemical, and physical character of Lake Michigan in the vicinity of the Donald C. Cook Nuclear Plant. Spec. Rep. 51. Gt Lakes Res. Div., Univ. Mich., Ann Arbor, Mich.: $5-138$.

Mozley, S. C., 1975. Preoperational investigations of zoobenthos in southeastern Lake Michigan near the Cook Nuclear Plant. Spec. Rep. 56. Gt Lakes Res. Div., Univ. Mich., Ann Arbor, Mich., 132 pp.

Mozley, S. C. \& R. P. Howmiller, 1977. Environmental status of the Lake Michigan region, 6. Benthos of Lake Michigan. Argonne Nation. Lab. ANL/ES-40. Argonne, Ill., 48 pp.

Mozley, S. C. \& M. H. Winnell, 1975. Macrozoobenthic species assemblages of southeastern Lake Michigan, U.S.A. Verh. int. Ver. Limnol. 19: 922-931.

Nalepa, T. F. \& N. A. Thomas, 1976. Distribution of macrobenthic species in Lake Ontario in relation to sources of pollution and sediment paraneters. J. Gt Lakes Res. 2: 150-163.

Saether, O. A., 1975a. Nearctic and palaearctic Heterotrissocladius (Diptera: Chironomidae). Bull. Fish. Bd Can. 193. 67 pp.

Saether, O. A., 1975b. Nearctic chironomids as indicators of lake typology. Verh. int. Ver. Limnol. 19: 3127-3133.

Saether, O. A., 1979. Chironomid communities as water quality indicators. Holoarc. Ecol. 2: 65-74.

Schelske, C. L., E. F. Stoermer, D. J. Conley, J. A. Robbins \& R. M. Glover, 1983. Early eutrophication of the lower Great Lakes: New evidence from biogenic silica in the sediments. Science 222: $320-322$.

Seibel, E. \& J. C. Ayers, (eds). The biological, chemical, and physical character of Lake Michigan in the vicinity of the 
Donald C. Cook Nuclear Plant. Spec. Rep. 51. Gt Lakes Res. Div., Univ. Mich., Ann Arbor, Mich., 475 pp.

Teter, H. E., 1960. The bottom fauna of Lake Huron. Trans. am. Fish. Soc. 89: 193-197.

Winnell, M. H. \& D. H. Jude, 1980. Spatial and temporal distribution of benthic macroinvertebrates and sediments collected in the vicinity of the J. H. Campbell Plant, eastern Lake Michigan, 1979. Spec. Rep. 77. Gt Lakes Res. Div., Univ. Mich., Ann Arbor, Mich., 132 pp.
Winnell, M. H., 1984. Chironomidae (and other Diptera), 6. In: D. S. White (ed.), Ecology of the Zoobenthos of Southeastern Lake Michigan Near the D. C. Cook Nuclear Power Plant. Spec. Rep. 100. Gt Lakes Res. Div., Univ., Mich., Ann Arbor, Mich., 177 pp.

Received 23 March 1985, in revised form 11 June 1985; accepted 10 July 1985. 